\title{
References:
}

1. Якобсон А.И., Полищук $\Lambda$.И., Беневоленский В.Б. Пенсионная система: модель Аля россии и зарубежный опыт. - М.: РеАакционная коммегия серии «Независимый экономический анализ», 2003.

2. Pension reform 2013. Annual Report. - Global and Georgian Perspective EPRC.

3. Georgian Law Regarding Non-state Pension Insurance and Activities.

4. Geletashvili Nino. Chilean Pension Reform: Its Essence and Meaning for Georgia. - 2013.

5. Annual Report of National Bank of Georgia. - 2013.

6. Law of Georgia Regarding State Pension.

7. Resolution No. 181, 2007, 29 August of the Government of Georgia: "Defining appendage to the state pension according to the length of service considering pension age".

8. Insurance Company ALDAGIBCI.// [Electronic resource]. - Available from: http://www.aldagibci.ge/pensionfund/

9. Insurance Company GPI HOLDING.// [Electronic resource]. - Available from: https://www.gpih.ge/gpih/pensionfund/

10. National Statistics Office of Georgia.// [Electronic resource]. - Available from: http://geostat.ge/

Yadgarova Malika Lutpillaevna, Tashkent Financial Institute, Senior teacher, Department of "Banking"

Hudoyarova Hurshida Abdinazarovna, Senior teacher, Department of "Banking"

E-mail:nasibaturgunowna@mail.ru

\section{The role of monetary policy in macroeconomic regulation Uzbekistan}

Abstract: Minimum (mandatory) reserves - is the most liquid assets, which are required to have all credit institutions, as a rule, either in the form of cash on hand or in the form of deposits with the Central Bank or other forms of highly determined by the Central Bank Uzbekistan.

In Uzbekistan, the impact of this policy in the money supply is used as the main tool.

Keywords: monetary sphere, bank deposit, inflation, liquidity.

Ядгарова Малика Аутпилмаевна, Ташкентский Финансовый институт, стариий преподаватель, кафедра "Банковское дело"

Худалрова Хуршида Абдиназаровна, стариий преподаватель, кафедра "Банковское дено"

E-mail:nasibaturgunowna@mail.ru

\section{Роль денежно-кредитной политики в макроэкономическом регулировании Узбекистана}

Аннотация: Минимальные (обязательные) резервы - это наиболее киквидные активы, которые обязаны иметь все кредитные учреждения, как правило, либо в форме наличных денег в кассе банков, мибо в виде Аепозитов в Центральном банке или в иных высоколиквидных формах, определяемых Центральным банком. Узбекистана. В Узбекистане влияние этой политики в структуре Аенежной массы используется в качестве основного инструмента.

Ключевые смова: денежно-кредитная сфера, банковский депозит, инфмяция, ликвидность. 
Аенежно-кредитная политика - это важнейшее направление экономической политики государства, преАставмяющая собой совокупность разработанных центральным банком совместно с правительством мероприятий в области организации денежных и кредитных отношений в стране. С помощью этих мероприятий обеспечивается воздействие Аенежнокредитной сферы на воспроизводственный процесс в целях регулирования экономического роста, повышения эффективности производства, обеспечения занятости населения, стабимьности внешнеэкономических связей и решение Аругих стратегических задач, стоящих переА экономикой кажАой страны.

Цели денежно-кредитной политики:

1) устойчивые темпы роста национального производства;

2) стабимьные цены;

3) высокий уровень занятости насемения;

4) равновесие платежного баланса.

Хотя денежно-кредитная политика определяется правительством страны, ее проводником является Центральный банк.

В законе "О Центральном банке Республики Узбекистан” принятый в 1995 году 21 декабря в III статье указано, что главной целью Центрального банка Узбекистана является обеспечение стабильности национальной валюты [1].

ЦБ располагает набором среАств, которые называются инструментами Аенежно-кредитной политики. Эти инструменты в основном возАействуют либо на количество денег, главным образом в виде банковских Аепозитов, Аибо на процентные ставки.

На первом этапе Центральный банк воздействует на преАложение Аенег, уровень процентных ставок, объем кредитов. На втором - изменения в данных факторах передаются в сферу производства, способствуя достижению конечных целей.

Инструменты денежно-кредитной политики не обязательно используются по отАельности, а наоборот, обычно используется сразу Ава инструмента и более, чтобы их эффекты взаимно усиливали Аруг Аруга. Мероприятия подобного рода называются комплексной политикой.

По непосреАственным объектам воздействия. В зависимости от конкретных целей денежно-кредитная политика направлена мибо на стимулирование креАитной эмиссии (кредитная экспансия), Аибо на ее ограничение (кредитная рестрикция). КреАитная экспансия проводится Аля увеличения занятости и подъема производства, а креАитная рестрикция, чтобы предотвратить «перегрев» экономики или чтобы понизить темпы инфмяции.

Основными общими инструментами кредитно-Аенежной политики явмяются:

1) изменение нормы обязательного резервирования;

2) изменение учетной ставки (ставки рефинансирования);

3) операции на открытом рынке.

Политика обязательных резервов. Минимальные (обязательные) резервы - это наиболее киквиАные активы, которые обязаны иметь все кредитные учреждения, как правило, мибо в форме наличных Аенег в кассе банков, Аибо в виде депозитов в Центральном банке или в иных высоколиквидных формах, определяемых Центральным банком Узбекистана.

В Узбекистане вмияние этой политики в структуре Аенежной массы используется в качестве основного инструмента. В Аанное время это составляет в национальном и иностранной валюте $15 \%$.

Если сравнить это с зарубежными странами, мы видим, что это очень высокий показатель. Например, в Белорусский это $10 \%$, в Польше - 3,5\%, в Чехии $2 \%$, в Швейцарии $-2,5 \%$, в Венгрии - $5 \%$. Если мы посмотрим, что инфмяция в стране составила $6,1 \%$, то мы видим, что обязательные резервы остаются высокими.

Изменением нормы обязательных резервов Центральный банк подАерживает степень миквидности коммерческих банков на минимально допустимом уровне в зависимости от экономической ситуации. Он являются инструментом, используемым Центральным банком Аля регулирования объема денежной массы в стране. Изменение нормы обязательных резервов влияет на рентабельность кредитных учрежАений еще, Аанный метод служит наиболее эффективным антиинфмяционным среАством.

Этот инструмент монетарной политики явмяется наиболее мощным, поскольку он затрагивает основы всей банковской системы. Он является настолько мощным, что в действительности его применяют раз в несколько мет, а не каждый день, как в случае с операциями на открытом рынке.

Рефинансирование коммерческих банков. Рефинансирование означает получение денежных среАств креАитными учрежАениями от Центрального банка.

Центральный банк может выдавать кредиты коммерческим банкам, по ставку рефинансирования. Векселя переучитываются по ставке редисконтирования. 
Эту ставку называют также официальной дисконтной ставкой, обычно она отличается от ставки по кредитам. Стоит отметит, в Узбекистане вексель и вексельные обращения прекращены с 1997 года.

Изменение учетной (рефинансирования) ставки прямо влияет на изменение ставок по креАитам коммерческих банков. Последнее явмяется главной целью Аанного метода Аенежно-кредитной политики Центрального банка. Например, повышение официальной учетной ставки в периоА усимения инфмяции вызывает рост процентной ставки по кредитным операциям коммерческих банков, что приводит к их сокращению, поскольку происходит удорожание креАита, и наоборот. С 1 января 2015 года в Узбекистане ставка рефинансирования понизили с 10 Ао $9 \%$. По сравнению с некоторыми странами, Россия - 0,25, в Соединенных Штатах - 8,24, в Японии $-0,1 \%, 1 \%$ в
Европейском Союзе, в нашей республике они остаются относительно высокими.

Изменение официальной процентной ставки оказывает влияние на кредитную сферу:

1) затруднение или облегчение возможности коммерческих банков получить кредит в Центральном банке влияет на миквидность кредитных учреждений;

2) изменение официальной ставки означает удорожание или удешевление кредита коммерческих банков Аля клиентуры, так как происходит изменение процентных ставок по активным кредитным операциям.

Недостатком использования рефинансирования при проведении денежно-кредитной политики явмяется то, что этот метод затрагивает лишь коммерческие банки. Если рефинансирование используется мало или осуществмяется не в Центральном банке, то указанный метоА почти полностью теряет свою эффективность.

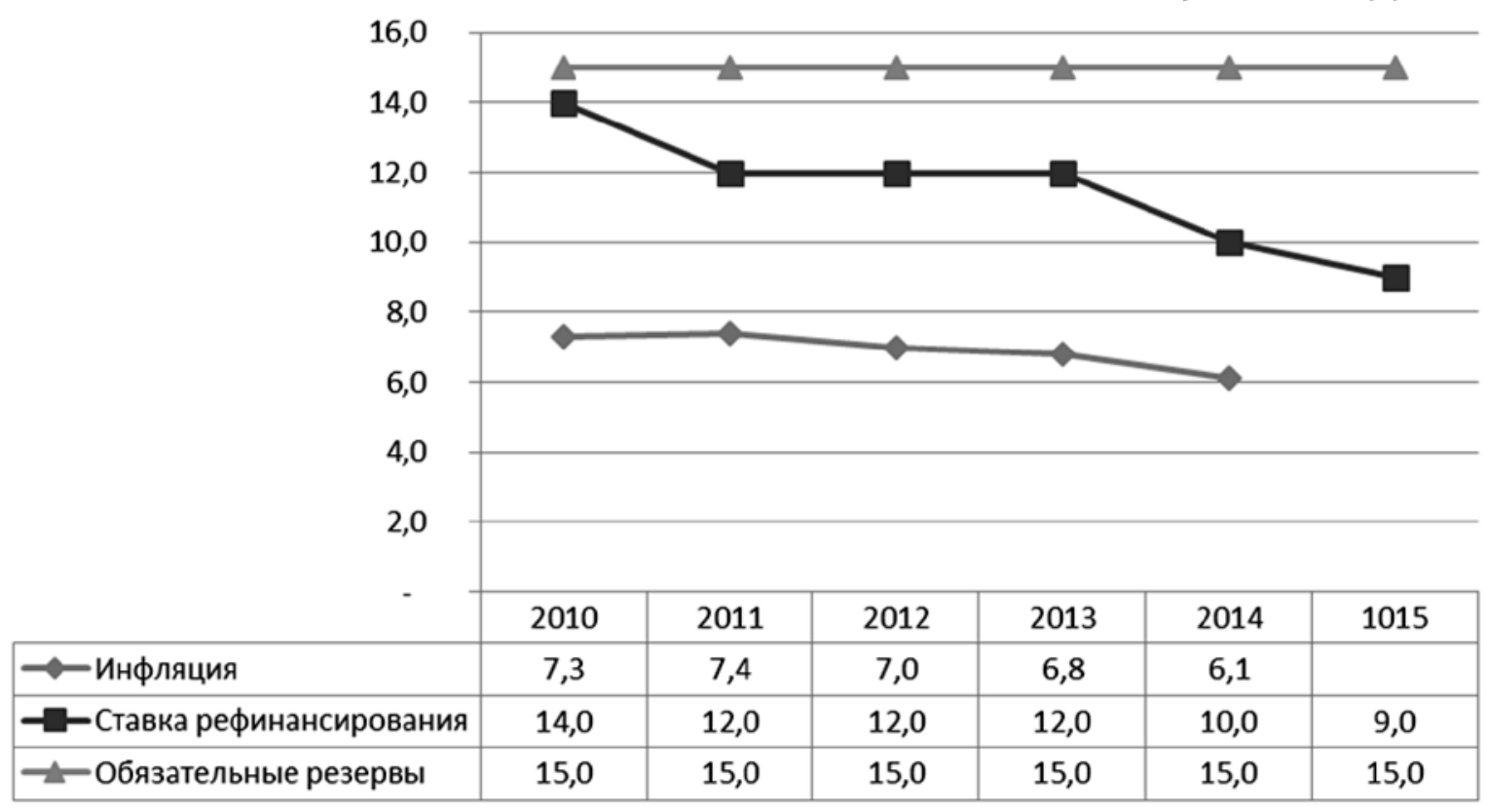

Рис. 1. Изменение денежно-кредитной политики и инфляции [2]

Операции на открытом рынке. ГАавным инструментом денежно-кредитной политики стали интервенции Центрального банка, получившие название операций на открытом рынке. Этот заключается в том, что Центральный банк осуществмяет операции купли-проАажи ценных бумаг в банковской системе. Объектами открытого рынка является государственные ценные бумаги. Приобретение ценных бумаг у коммерческих банков увеличивает ресурсы последних, соответственно повышая их кредитные возможности, и наоборот, Центральные банки периодически вносят изменения в указанный метоА кредитного регулирования, изменяют интенсивность своих операций, их частоту.

Операции на открытом рынке впервые стали активно применяться в США, Канаде и Великобри- тании в связи с наличием в этих странах развитого рынка ценных бумаг. Позднее этот метод креАитного регулирования получим всеобщее применение и в Западной Европе. ГАавное отличие Аанного метоАа - это использование более гибкого регулирования, поскольку объем покупки ценных бумаг, а также используемая при этом процентная ставка могут изменяться ежедневно в соответствии с направлением политики Центрального банка. Коммерческие банки, учитывая указанную особенность данного метоАа, Аолжны внимательно следить за своим финансовым положением, не Аопуская при этом ухудшения Аиквидности.

Стоит отметить, что эмиссия государственных облигаций в Узбекистане остановлено с 2014 года. Из-за 
этого Аля влияние на Аенежную массу Аанный инструмент не явмяется мощным как в зарубежный странах.

В общем, использование инструментов денежнокреАитной политики в стране, можно сАелать слеАующие преАложения по улучшению:
1. Аомжны быть преАприняты кредитные эксрансии. Сокращение требований по обязательным резервам на 7-8\%, а в депозитах в иностранной валюте Аобиться снижения на 5 процентов. Таким способом можно Аобиться Аешевых креАитов и роста ВВП.

\section{Список митературы:}

1. Закон о Центральном банке Узбекистана. 21.12.1993г.//[Электронный ресурс]. - Режим доступа: http://www.cbu.uz

2. Маврушкин О.И. Учебник “Банковское демо”. - Ташкент: ТМИ, 2008 - 108 с. 